\title{
Identificación de Lactobacillus sp con potencial probiótico a partir de sustrato fermentado de yuca (Manihot esculenta)
}

\section{Identification of Lactobacillus sp with probiotic potential from fermented yuca (Manihot esculenta)}

\author{
Roger Antonio Urbina Orozco ${ }^{1}$, Kels Rahomi Guerrero Montenegroº ${ }^{1}$ Wendell Antonio Mejía Tinoco ${ }^{2}$, Isaías Ezequie ${ }^{1}$ \\ Sánchez Gómez ${ }^{3}$, Jannin Ronaldo Hernández Blandón ${ }^{4}$ \\ 'Ingeniero Zootecnista, ORCID: https://orcid.org/0000-0002-8268-3532 / ORCDI: https://orcid.org/0000-0001-9878-7507. ${ }^{2}$ MSc.en \\ Biotecnología / ${ }^{3}$ MSc. en Sanidad Vegetal, ORCID: https://orcid.org/0000-0002-6604-1660 isanchez@ci.una.edu.ni /4 Ingeniero Zootecnista. \\ Universidad Nacional Agraria
}

\section{RESUMEN}

En Nicaragua sistemas de producción pecuaria se ven afectados por la baja disponibilidad de alimento y agua en la época seca, ocasionando el aumento de enfermedades y desnutrición, afectando directamente los parámetros productivos y reproductivos del hato. De igual forma para contrarrestar este tipo de situaciones entra el uso de antibióticos de uso profiláctico, terapéuticos y promotores de crecimientos capases de eliminar patógenos y actuar de manera drástica sobre la flora microbiana necesaria para el funcionamiento del aparato digestivo además de influir en la acumulación de residuos en los productos finales de importancia para los consumidores. El género lactobacillus representa un alto potencial biotecnológico, estas bacterias contribuyen al desarrollo de características organolépticas de los alimentos y generan un ambiente poco favorable para el desarrollo de microorganismos patógenos. El objetivo de este trabajo fue identificar mediantes pruebas in vitro las especies de Lactobacillus con potencial probiotico procedentes de sustrato fermentado de yuca. Mediante las pruebas bioquímicas se identificaron dos lactobacillus sp, L. casei y L. Brevis. Las especies de Lactobacillus previamente identificadas fueron sometidas la prueba de resistencia a diferentes niveles de $\mathrm{pH}$, mostrando resistencia a las condiciones acidas. La prueba de antagonismo microbiano frente $E$. Coli ATCC 25922 y Salmonella sp, demostraron presencia de halos de inhibición, indicando acción antimicrobiana sobre el crecimiento de los patógenos. Las especies de L. casei y L. Brevis fueron sensibles a los antibióticos Trimetropim Sulfametaxona y oxitetraciclina al realizar la prueba de sensibilidad. Estos resultados demuestran que las cepas identificadas pueden ser utilizadas como probiótico en la alimentación de los animales o como inoculante en el proceso de ensilaje.

Palabras clave: probiotico, antagonismo, tolerancia, especie.

\section{ABSTRACT}

In Nicaragua systems of production cattle they are affected by the low availability of food and water in dry season causing the increase of diseases and malnutrition, affecting directly the productive and reproductive herd parameter, Likewise counteract this types of situations comes the of antibiotics by prophylactic therapeutic use and growth promoters, able to eliminate pathogens and eliminate drastically on the microbial flora necessary for the functioning or the digestive system also to influencing the accumulation of waste in final products of importance to consumers, the genus lactobacillus represents a high biotechnological potential, this bacteria contribute to the increase organoleptic of food and generate an unfavorable environment for the growth of pathogens microorganisms. The objective of this work was identify with vitro test the species of lactobacillus with high probiotic through fermented substrate of yucca, through biochemical tests, lactobacillus sp, L.casei and L.brevis was identified, the lactobacillus species previously identified was in a resistance tests with different level of $\mathrm{pH}$ showing resistance to the acid conditions, the microbial antagonism test in front E.coli ATCC 25922 and salmonella sp demonstrate the presence of inhibition of halos, showing antimicrobial action over the pathogens growth the L.casei and L.brevis species was sensitive to Trimetoprim sulfametaxona and oxitetraciclina antibiotics, to realize the sensitive tests. These results demonstrate that the identified strains can be used as a probiotic in the feeding of the animals or as an inoculant in the silage process.

Keywords: Probiotic, antagonism, tolerance, species.
Recibido: 12 de junio del 2018

Aceptado: 29 de octubre del 2018

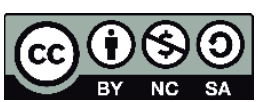

Los artículos de la revista La Calera de la Universidad Nacional Agraria, Nicaragua, se comparten bajo términos de la licencia Creative Commons: Reconocimiento, No Comercial, Compartir Igual. Las autorizaciones adicionales a las aquí delimitadas se pueden obtener en el correo freddy.aleman@ci.una.edu.ni

C) Copyright 2018. Universidad Nacional Agraria 


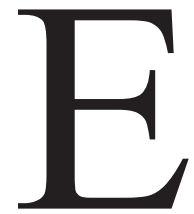

n los sistemas ganaderos de américa central es común el uso de diferentes estrategias para la alimentación del ganado, las que se destacan el pastoreo, el uso de ensilajes, henos y la suplementación con concentrados artesanales. En Nicaragua existen una época seca, durante las cuales la oferta de forrajes es deficiente y en consecuencia afecta negativamente los paramentos productivos y reproductivos de la ganadería. Los recursos usados en la época seca como alimento se caracterizan por presentar bajos valores nutritivos (Fujisaka et al., 2005).

En época de verano la productividad del ganado se ve afectada por la escasez de alimento y agua, así mismo el aumento en los índices de enfermedades y desnutrición. Al llegar la época de invierno, se asume el reto de recuperar las pérdidas ocasionadas por el manejo inadecuado de los animales y las condiciones ambientales del verano, para lograr obtener mejores ganancias y una productividad rentable en términos económicos (Vives, 2012).

En la producción animal se persigue siempre conseguir una buena situación sanitaria y de rendimiento en los parámetros productivos para obtener resultados económicos rentables manteniendo una relación directa entre el funcionamiento del tracto intestinal, la tasa de crecimiento, índice de conversión y las diversas enfermedades que conlleva a someter al ganado a tratamientos con antibióticos o quimio-terapéuticos, capaces de eliminar tanto patógenos como la flora bacteriana necesaria para el funcionamiento del aparato digestivo (García, 2016).

La búsqueda de nuevas alternativas a los antibióticos promotores de crecimiento se ha incrementado y actualmente se buscan compuestos que aumenten la inmunidad del huésped y no tengan efectos secundarios o residuales en los productos de origen animal. Los probiotico tiene gran potencial por su efecto modulador de la microbiota del tracto gastrointestinal que genera efectos positivos en el huésped (Giraldo et al., 2015).

El género Lactobacillus representan un alto potencial biotecnológico, dada su presencia en diversos procesos fermentativos de alimentos destinados al consumo humano y animal. Estas bacterias contribuyen al desarrollo de las características organolépticas de los alimentos, además generan ambientes poco favorables para el desarrollo de microorganismos patógenos, debido a su marcada capacidad antagonista (Rondón et al., 2008). Las especies Lactobacillus son una alternativa al uso del antibiótico con el fin de equilibrar la microbiota intestinal mejorando la asimilación de nutrientes y disminuir los residuos de fármacos en alimentos de origen animal considerándolo como un factor de riesgo en la salud pública (Lozano et al., 2008).

El objetivo de este estudio es identificar especies del género Lactobacillus con potencial probiotico en sustrato fermentado de yuca (Manihot esculenta), para suministrarse como una alternativa alimenticia de bajo costo en los sistemas de producción logrando potenciar y aumentar la capacidad digestiva de los animales en producción.

\section{MATERIALES Y MÉTODOS}

Ubicación del estudio. El estudio se realizó en el laboratorio de microbiología de la Universidad Nacional Agraria, ubicado en el km 12 1/2 en las coordenadas geográficas $12^{\circ} 08^{\prime} 33^{\prime \prime}$ de latitud norte y $86^{\circ} 10^{\prime} 31$ " de longitud oeste (INETER, 2010).

Aislamiento de las bacterias ácido-lácticas. La muestra de sustrato fermentado de yuca fue obtenida siete días después de haber sido incubado utilizando 300 gramos de yuca fresca como sustrato en $500 \mathrm{ml}$ de agua destilada y seis gramos de melaza. Posteriormente el sustrato fue trasladado al laboratorio para su análisis. El aislamiento de bacterias acido lácticas (BAL) se realizó por el método de dilución en serie, el cual consiste en homogenizar la muestra y de esta tomar $1 \mathrm{ml}$ del sustrato para ser diluido de manera higiénica al diluente (agua destilada) y ser homogenizada. Preparada la dilución madre $\left(10^{-1}\right)$ se procedió a preparar diluciones decimales subsiguientes, para cada dilución se utilizaron tubos con $9 \mathrm{ml}$ de agua destilada (se traspasó $1 \mathrm{ml}$ ) a la siguiente dilución $\left(10^{-2}\right) \mathrm{se}$ realizó el mismo procedimiento hasta formar la dilución $\left(10^{-7}\right)$ (Gutiérrez, 2012).

Se inocularon platos Petri con medio MRS previamente esterilizados con alícuotas de $0,1 \mathrm{ml}$ de las diluciones $10^{-4}, 10^{-5}$ y $10^{-6}$ esparcida con ayuda de un asa Drigalsky sobre la superficie del medio, se hizo de manera triplicada para ambas diluciones. Estas se incubaron en jarras de anaerobiosis por un periodo de 24 a 48 horas a $30^{\circ} \mathrm{C}$. Posterior al periodo de incubacion unas ves ya con un resultado de crecimiento de colonias bacterianas se tomaron las colonias para proceder nuevamente hacer inoculadas en medios MRS utilizando un asa redonda realizando rayado estriado en tres direcciones, estas se incubaron nuevamente por un periodo de 24 a 48 horas a $30^{\circ} \mathrm{C}$ con la finalidad de obtener colonias más puras.

Identificación de las cepas de Lactobacillus. Se realizaron observaciones de colonias bacterianas aisladas mediante coloración Gram al microscopio óptico y se con- 
servaron únicamente las que presentaron morfologia de bacilos. Posteriormente se realizaron determinación de esporas y pruebas de fermentación de carbohidratos tales como: lactosa, sacarosa, manitol, sorbitol xilosa.

Prueba de resistencia a diferentes tipos de pH. Se inoculo con un asa bacteriológica $3 \mathrm{ml}$ de caldo MRS ajustado a $\mathrm{pH} 1.5$ a 6.0 con intervalos de 0.5 con $\mathrm{HCl} 1 \mathrm{~N}$ y se incubaron a $30^{\circ} \mathrm{C}$ durante 24 horas en condiciones de microaerofilia (Mantilla y Burgos, 2012). Posteriormente se midió la turbidez del medio para demostrar la viabilidad de las colonias.

Capacidad antagónica de las cepas Lactobacillus sobre bacterias patógenas. Se utilizaron colonias previamente identificadas de Lactobacillus sp, resistentes a diferentes grados de $\mathrm{pH}$, posteriormente se sometieron a la prueba de antagonismo mediante el método de Kirby-Bauer (1966) el cual consiste en utilizar el medio solido Miuller Hilton inoculado con la cepa bacteriana Escherichia coli ATCC 25922 y Salmonella sp, respectivamente a una concentración $1 \times 108$ ( 0.5 grado de turbidez escala Mackfarland), posteriormente se impregnaron discos de papel filtro esterilizados de $0.5 \mathrm{~mm}$ de diámetro con las bacterias acido lácticas identificadas (CNDR, 2004). Las placas se encubaron por un periodo de 24 a 48 horas a $30^{\circ} \mathrm{C}$ en condiciones de aerobiosis posterior al periodo de incubación se verificó la actividad antagónica por la formación de zonas trasparentes alrededor de las colonias con un diámetro mayor a $1 \mathrm{~mm}$.

Prueba de sensibilidad a antibiótico. Las colonias de bacterias previamente identificadas como Lactobacillus, y resistentes a diferentes grados de $\mathrm{pH}$, fueron sometidas a pruebas de sensibilidad a antibióticos a través del método de Kirby-Bauer (1966) consiste en colocar discos de papel impregnados de antibióticos en la superficie del medio previamente inoculado con una suspensión bacteriana 0,5 Mackfarland. Se produce la difusión de antibiótico y el crecimiento bacteriano en la superficie del medio. En el área donde la concentración de antibiótico es suficiente para evitar el crecimiento bacteriano se observa un halo de inhibición con borde definido claramente y con el disco ubicado en el centro del círculo (CNDR, 2004). Para el estudio se utilizaron los medios de cultivos Müller Hilton y medio MRS con previa colocación de los discos con antibióticos según las normas NCCLS (Oxitetraciclina 30 $\mu \mathrm{g}$, Trimetropim Sulfametaxona $25 \mu \mathrm{g}$ ) las placas se incubaron en jarras de anaerobiosis por un periodo de 24 a 48 horas a $30^{\circ} \mathrm{C}$ posterior al tiempo de incubación la lectura fue efec- tuada por la medición del diámetro de la zona (Halo) de inhibición.

\section{RESULTADOS Y DISCUSIÓN}

Identificación de especies Lactobacillus. A partir de la muestra de sustrato de yuca fermentada, se aislaron diez colonias bacterianas y una colonia de levadura en platos Petri conteniendo agar MRS. Las observaciones microscópicas en siete aislados bacterianos con tinción Gram mostraron morfología compatible con Lactobacillus sp, mientras que dos mostraron morfología para Bacillus Gram negativos y un único aislado con Bacillus Gram positivos. Mediante pruebas bioquímicas identificaron las especies de Lactobacillus casei y brevis.

Las especies de $L$. casei y $L$. brevis son bacteria facultativamente heterofermentativa, encontrándose en diferentes hábitats tales como productos lácteos, ensilaje, tractos intestinales humanos, bocas y aguas residuales (Collins et al., 1989), L. casei es productora de ácido láctico predominantemente de la forma isomérica $\mathrm{L}(+)$, se le considera generalmente como segura (GRAS) y tiene un amplio número de aplicaciones en la industria alimentaria (Arellano et al., 2013).

Estudio realizado por Velásquez et al.,2015, describe a Lactobacillus casei como una bacteria probiótica muy eficaz para equilibrar la microflora intestinal, prevenir los trastornos intestinales, regular el sistema inmune específicamente de la respuesta inmune celular y además posee una potente acción antidiarreica. Lactobacillus brevis es tolerante a los jugos gastro intestinales, tiene la capacidad de mejor la salud intestinal se ha utilizado en terapias de intestino irritables. Lactobacillus brevis son tradicionalmente utilizados en productos fermentados esta cepa actualmente es una de la más utilizada como probiotico (Ronka et al., 2003).

Los resultados del estudio pueden ser utilizados para mejorar la especificidad y selectividad de microorganismos probiótico a partir de la incorporación de bacterias acido lácticas a sustratos fermentados de yuca u otro tipo de sustrato de origen vegetal y animal.

Prueba de tolerancia a pH. Los siete aislados de Lactobacillus fueron sometidos a la prueba de tolerancia a $\mathrm{pH}$, observándose crecimiento bacteriano únicamente en las especies identificadas como Lactobacillus brevis y Lactobacillus casei. Para los géneros de Lactobacillus sp, las condiciones de $\mathrm{pH}$ no fueron favorables para su crecimiento (cuadro 1).

Rodríguez et al., (2008) afirma que el comportamiento de los cultivos del género Lactobacillus 
Cuadro 1. Prueba tolerancia de Lactobacillus sp a diferentes niveles de $\mathrm{pH}$

\begin{tabular}{|c|c|c|c|c|c|c|c|c|c|c|}
\hline \multirow{2}{*}{$\begin{array}{c}\text { Especies } \\
\text { identificadas }\end{array}$} & \multicolumn{10}{|c|}{ Concentración } \\
\hline & $\mathrm{pH} 1.5$ & $\mathrm{pH} 2$ & pH 2.5 & pH 3 & $\mathrm{pH} 3.5$ & $\mathrm{pH} 4$ & $\mathrm{pH} 4.5$ & $\mathrm{pH} 5$ & pH 5.5 & $\mathrm{pH} 6$ \\
\hline L. casei & + & + & + & + & + & + & + & + & + & + \\
\hline Lactobacillus sp & - & - & - & - & - & - & - & - & - & - \\
\hline Lactobacillus sp & - & - & - & - & - & - & - & - & - & - \\
\hline L. brevis & + & + & + & + & + & + & + & + & + & + \\
\hline L. casei & + & + & + & + & + & + & + & + & + & + \\
\hline L. casei & + & + & + & + & + & + & + & + & + & + \\
\hline L. casei & + & + & + & + & + & + & + & + & + & + \\
\hline
\end{tabular}

Positivo (+). Crecimiento de las cepas, Negativo (-). Ningún crecimiento.

frente a niveles de $\mathrm{pH}$ bajos son capaces de sobrevivir en condiciones de acidez similares a las existentes en el estómago de animales y seres humanos. (Mandingan et al., 2004) menciona que el género Lactobacillus es más resistentes a condiciones acidas que otras bacterias lácticas siendo capaces de crecer aun cuando el $\mathrm{pH}$ haiga caído tanto permitiéndole crecer durante la fermentación láctica natural.

(Carr y col, 2002, citado por Ramírez et al., 2011) indica que las BAL son acido tolerantes pudiendo crecer en $\mathrm{pH}$ tan bajos como 3.2 otras a valores tan altos como 9.6 y la mayoría crece a $\mathrm{pH}$ entre 4 y 4.5 permitiéndoles sobrevivir naturalmente en medios donde otras bacterias no tolerarían el $\mathrm{pH}$ acido.

León (2012) hace referencia a la resistencia de los Lactobacillus a niveles de $\mathrm{pH}$ acido, por presencia de una gradiente constante entre el $\mathrm{pH}$ extracelular y el $\mathrm{pH}$ citoplasmático los microorganismos GRAM positivo utilizan un mecanismo conocido como F1-F0ATPasa.

Capacidad antagónica de las cepas Lactobacillus sobre bacterias patógenas. Las especies Lactobacillus casei y brevis exhibieron actividad antagónica contra el patógenos E. coli ATCC 25922 y Salmonella sp, observándose halos de inhibición con diámetro de $10 \mathrm{~mm}$, indicando que los aislados identificado tienen la capacidad de inhibir el crecimiento del patógeno (figura 1).

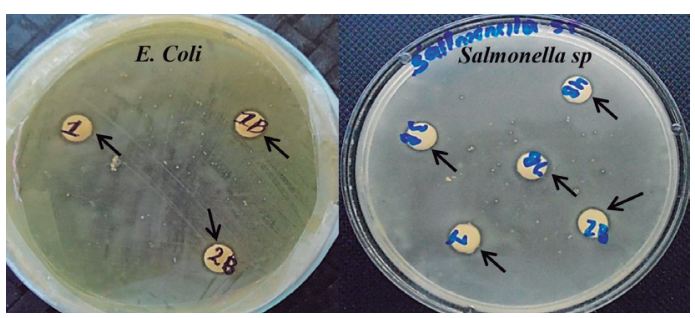

Figura 1. Halos de inhibición (Flechas) observados en prueba de antagonismo microbiano de $L$. casei y $L$. brevis frente a $E$. coli ATCC 25922 (Izquierda) y Salmonella sp (Derecha). 2B: cepa de Lactobacillus brevis, 1, 4B, 3B Y 1B: cepa de Lactobacillus Casei.
Los resultados obtenidos en el presente estudio se asimilan con los de (Benítez, 2015) en donde se evaluó la capacidad antagónica de cuatro aislamientos de Lactobacillus sp; frente a las bacterias patógenas E. Coli y Salmonella sp en el cual los aislados presentan una gran actividad antimicrobiana. De igual manera (Amorocho, 2011) indico que la actividad inhibitoria frente a Salmonella de las especies Lactobacillus podría deberse a los componentes celulares, exclusión competitiva por nutrientes, a la presencia de ácido láctico y otras sustancias activas a $\mathrm{pH}$ bajo.

Estudio realizado por (Sánchez et al., 2011) se obtuvieron resultados similares a los del presente, en donde se avaluaron los aislados de Lactobacillus sp frente a E. Coli 25922 y se determinó la producción de ácidos orgánicos que inhibieron el crecimiento de E. Coli.

En este estudio no se evaluó la naturaleza de los procesos de producción de sustancia antagónica de las cepas previamente identificadas Lactobacillus brevis y Lactobacillus casei pero en un estudio realizado por (Ferreira et al., 2011) describe que en esta actividad pueden estar presentes ácido láctico, peróxido de hidrógeno, dióxido de carbono, di acetilo, acetaldehído y sustancias de naturaleza proteica antimicrobiana, llamadas bacteriocinas (Cabezas, 2005, citado por Gaitan, 2013) las bacteriocinas son sustancias extracelulares diferentes a los antibioticos que son producidas de forma natural por especies del género lactobacillus estas bacteriocinas inhiben el crecimiento a diferentes especies patógenas.

Mateau et al., (1997); citado por García et al., (2009) manifiestan que las bacterias del género Lactobacillus además de producir sustancias antagónicas pueden llegar a prevenir o tratar diversas enfermedades gastrointestinales compitiendo por sitios específicos contra las bacterias patógenas (Gaitan, 2013) menciona que se puede dar también una actividad antimicrobiana por la competencia de nutrientes que se encuentren en el intestino. 
Prueba de sensibilidad a antibiótico. Los aislados de Lactobacillus casei y Lactobacillus Brevis fueron sensibles a Trimetropim Sulfametaxona, debido a que se observaron halos de inhibición mayores a $19 \mathrm{~mm}$, también fueron sensibles a oxitetraciclina con halos de inhibición mayores a $15 \mathrm{~mm}$ (figura 2). Según los criterios de la NCCLS un microorganismo es sensible a Trimetoprim Sulfametaxona si el halo de inhibición es mayor o igual a 19 $\mathrm{mm}$ y son resistentes si el halo es menor o igual a $10 \mathrm{~mm}$, en relación a oxitetraciclina los microorganismos son sensibles si los halos son mayores o igual a $15 \mathrm{~mm}$ y son resistentes si presentan halos menores o igual $11 \mathrm{~mm}$.

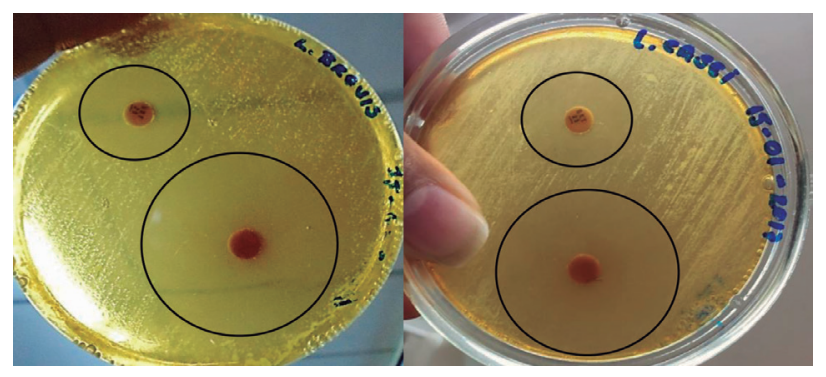

Figura 2. Prueba de sensibilidad de Lactobacillus brevis (Izquierda) y Lactobacillus casei (derecha) frente a los antibioticos Trimetoprim Sulfametaxona y Oxitetraciclina.

Los resultados obtenidos en el estudio son similares a encontrados por Lara, 2009 quien refiere que las cepas de Lactobacillus especies son susceptibles a oxitetrac- iclina debido a que no se observa crecimiento bacteriano en presencia del antibiótico, (Moreno, 2012) evaluó la susceptibilidad de las cepas aisladas de Lactobacillus sp frente al antibiótico Trimetoprim Sulfametaxona, obteniendo como resultado las cepas fueron sensibles a este antibiótico.

De igual manera (Jurado et al., 2009) evaluó cepas de Lactobacillus sp con oxitetraciclina en la cual las cepas fueron sensibles. La sensibilidad de las cepas podría depender de la resistencia a ciertas concentraciones de antibióticos, debido a la presencia de algunos plásmidos, o a propiedades particulares de la pared y membrana de estos microorganismos haciéndolos impermeables a antibióticos. Los resultados también coinciden con estudio realizado por Rodriguez, 2009 en la que destaca a las cepas de Lactobacillus como sensibles a la mayoría de los antibioticos de elección en terapias humanas y veterinaria.

\section{CONCLUSIONES}

Se identificaron especies de Lactobacillus sp, Lactobacillus casei y Lactobacillus brevis por medio de pruebas de fermentación de carbohidratos. Las cepas de Lactobacillus casei y Lactobacillus brevis presentaron resistencias a niveles bajos de $\mathrm{pH}$ y mostraron antagonismo al enfrentarlas a la cepa bacteriana E. coli ATTC 25922 y Salmonella sp., sin embargo, resultaron ser sensible al antibiótico Trimetropin-sulfametazona y Oxitetraciclina.

\section{REFERENCIAS BIBLIOGRÁFICAS}

Amorocho Cruz, C. 2011. Caracterización y potencial probiotico de bacterias lácticas aisladas de leche de oveja guirra. Tesis Doctoral. Valencia, España. Universidad politécnica de valencia. NI 253.

Arellano Arriaga, A. 2013. Evaluación del proceso y separación de ácido láctico a partir de la fermentación de suero lácteo mediante tecnología de membrana. Tesis de grado. Universidad Nacional de Querétaro. Querétaro, México. NI 109.

CNDR (Centró Nacional de Diagnóstico y Referencia). 2004. Manual de Procedimientos de Bacteriología Médica. Managua, NI p 273-297.

Collins, M; Phillips, B; Zanoni, P. 1989. Deoxyribonucleic Acid Homology Studies of Lactobacillus casei, Lactobacillus paracasei sp. nov., subsp. paracasei and subsp. tolerans, and Lactobacillus rhamnosus sp. nov., comb. Nov. International journal of systematic bacteriology (39) (2) 105-108.

Ferreira Barbosa, F; Jardim de Lima Barbosa, L; Silva Bambirra, L; Figueira Aburjaile, F. 2011. Produção de substâncias envolvidas no fenômeno de antagonismo bacteriano. Revista de Biologia e Ciências da Terra 11(1): 1-10.

Fujisaka, F; Holmann, M; Peters, A; Schmidt, D; White, C; Burgos, J; Ordoñez, M; Mena, M; Posas, H; Cruz, C; Hincapié, B. 2005. Estrategias para minimizar la escasez de forrajes en zonas con sequías prolongadas en Honduras y Nicaragua.

Gaitan Vaca, D. 2013. Aislamiento y evaluación de bacterias ácido lácticas con capacidad antagonica a partir de productos cárnicos madurados artesanalmente. Tesis de grado. Pontificia Universidad Javeriana. Bogotá, Colombia.

García Franco, A. 2016. Aislamiento, caracterización y determinación del potencial probiótico de bacterias lácticas de pollos. Tesis de pregrado. Universidad nacional del centro de buenos aires. Buenos aires, Argentina.

Garcia, A; Henríquez, P; Retamal, P; Pineda, S; Delgado, C; Gonzales, C. 2009. Propiedades probióticas de Lactobacillus sp aislados de biopsias gástricas de pacientes con y sin infección por Helicobacter pylori. Rev Méd Chile 137(1):369-376.

Giraldo Carmona, J; Narváez Solarte, W; Díaz López, E. 2015. Probiotico en cerdos: resultados contradictorios. Revista Biosalud 14(1):81-90.

Gutiérrez, Y. 2012. Universidad Nacional Agraria. Modulo práctico: técnicas de laboratorio. Managua. NI. 61 p.

Jurado, H; Aguirre, D; Ramírez, C. 2009. Caracterización de bacterias probiótica aisladas del intestino grueso de cerdos Como alternativa al uso de antibióticos. Rev.MVZ Córdoba 14(2):1723-1735. 
León Reissig, M. 2012. Evaluación in vitro de cepas de bacterias ácido lácticas nativas con potencial probiotico. Tesis de grado. Universidad de la Republica. Montevideo, Uruguay.

Lozano, M; Arias, D. 2008. Residuos de fármacos en alimentos de origen animal: panorama actual en Colombia. Revista colombiana de ciencias pecuaria 21(1):121-135.

Mantilla, C; Burgos, A. 2012. Potencial probiotico de cepas nativas para uso como aditivos en la alimentación avícola. Revista colombiana biotecnológica 14(1):31-40.

Moreno Galarza, L. 2012. Aislamiento y selección de Lactobacillus sp con potencial probiótico a partir de pan de abejas. Tesis de Magister en Ciencias-Microbiología. Bogotá, CO. Universidad Nacional de Colombia. NI 93.

Rodríguez, O; Perea, J; Martín, Y; Fernández, M; Padrón, I; Núñez de Villavicencio, M. 2008. Evaluación in vitro de resistencia de bacterias lácticas a la barrera gástrica y biliar de cerditos y a enterobacterias patógenas. Revista Computadorizada de Producción Porcina 15(3):277-271.

Rondón, A; Samaniego, M; Bocourt, R; Rodríguez, S; Milián, G; Ranilla, M; Laurencio, M; Pérez, M. 2008. Aislamiento, identificación y caracterización parcial de las propiedades probióticas de cepas de Lactobacillus sp. Procedentes del tracto gastrointestinal de pollos de ceba. Somenta 6(1):56-63.

Ronka, E; Malinen, E; Saarela, M; Rinta-Koski, M; Aarnikunnas, J; Palva, A. 2003. Probiotic and milk technological properties of Lactobacillus brevis. International Journal of Food Microbiology 83(1):63-74.

Sánchez, L; Vichi, J; Llanes, M; Castro, E; Soler, D; Espinosa, I; Kociubinski, G; Ferreira, C. 2011. Aislamiento y caracterización in vitro de cepas de Lactobacillus sp. como candidato a probióticas. Revista de Salud Animal 33(3):154-160.

Velásquez Téllez, J; Giraldo Giraldo, G; Padilla Sanabria, L; Giraldo Castaño, Y. 2015. Crecimiento de Lactobacillus casei ssp casei ATCC 393 en suero clarificado. Biotecnología en el Sector Agropecuario y Agroindustrial 13(1):19-27.

Vives Noguera, R. 2012. Suplementación estratégica y mejoramiento de la alimentación en época de verano. Tesis de grado. Antioquia, CO. Corporación Universitaria la Sallista. NI 102. 